\title{
A CHANGE OF VISION: \\ THE EMERGENCE OF THE SYSTEMS PARADIGM
}

\section{Patricia Perrin}

Art Education naturally has been shaped by changing concepts of the nature of art. During the period of time that has been designated as "Modern," it was thought that art had become autonomous and selfreferential, and no longer dealt with the real world. Based on that notion, some art programs in the schools have suffered from the belief that art does not give us meaningful information about the nature of reality. Lately, it has occurred to a number of theorists and critics in art and in literature, that a concept different from those definitions of "Modernism" may be more relevant.

It was not that art avoided reality, but that many of the arts, sciences, and philosophies redefined reality. Further development of this idea will help us to comprehend and communicate the relevance of our profession, since the idea that art is an autonomous and elite activity has led us into serious difficulties.

A change of vision began about a hundred years ago. It became visible around 1885 in the works of artists who seemed pressed by the necessities of new ways of seeing. In one way after another they sought to decipher and to communicate a different sense of the world.

That was a time for new visions. According to science historian Thomas Kuhn, "During revolutions scientists see new and different things when looking with familiar instruments in places they have looked before." 1 With their easels placed firmly in front of familiar landscapes, late 19th century painters made images that many others could not see. Landscapes in paintings began to move up to toward the viewer, and the ground began to surround and merge with the figure, or image. As space shifted, visual ambiguities appeared in paintings, 
ambiguities that characterized the later work of Monet and Cezanne and, by the time of the Cubists, could be identified as part of the content of the work.

Playwrights abandoned the naturalistic sequences which they had learned so well, and created episodes that were generated by internal causes, or by no apparent cause. Strindberg, Kaiser, and Pirandello worked with revised notions of causality, space and time.

Authors, also, confused their audiences with juxtapositions of images and word-sounds, and lost story lines. A different pattern of relationships of sounds and rhythms appeared in Hopkins' poetry, and later in writings by Stein, Woolf, Proust and Joyce. To many readers, writers seemed to have abandoned the idea of using language to communicate, and taken to building structures with it, instead.

Scientific theory shattered many assumptions about the nature of reality. Although he was innocent of such philosophical intentions, Einstein's theories of relativity were transformed into relativism. In recent years, terms from the fields of quantum physics, mathematics, and other sciences have been used to describe the nature of cultural change. References are made to field theory, the ecological model, and systems theory, among others. One of the things that these theories have in common is the focus on relationships rather than on anaylsis of separate things or events.

Katherine Hayles says that in the literary works she studies, the authors are "reacting not to science as such, but to a more general set of ideas pervasive in the culture." That set of ideas "is as capable of informing literary strategies as it is of forming scientific models." ${ }^{2}$ Perhaps this helps to explain why we now have scientists writing about philosophy and humanities, and philosophers making use of scientific paradigms. When everything is interrelated in a dynamic field, there is really no place to stop the investigation. Or, the stopping place must be arbitrarily imposed.

Historian Stephen Kern, like Marshall McLuhan, Alvin Toffler, and

Working Papers in Art Education 1987 
Walter Ong, sees some changes in world view that "were directly inspired by new technology." As examples of technological influence on the arts, he mentions Joyce's fascination with the cinema, the Futurists' worship of modern technology, and simultaneous poetry written "as a response to simultaneity of experience made possible by electronic communication." He addes that "many conceptions of time and space, however, were altered independently of technology, in response to pressures within various genres and disciplines," and that:

The thematic similarity between developments inspired by technology and those independent of it suggests that a cultural revolution of the broadest scope was taking place, one that involved essential structures of human experience and basic forms of human expression. ${ }^{3}$

Kern does not linger with examples between which he was not able to discover any actual connection. He is interested in developments that he is satisfied were causally or consciously related at the time they occurred. The present study, on the other hand, considers analogous developments, whether any causal connection can be determined or not, in relation to that "cultural revolution" which exposes a significant change in world view. In Einstein as Myth and Muse Friedman and Donley point out that "both causal relationships and parallels (not causally related) exist between the new literature and the new science." ${ }^{4}$ Milec Capek, writing about relationships between the ideas of Bergson, Whitehead, and Bohm, says that it is the very fact that ideas were developed independently "which makes the affinity even more significant." ${ }^{5}$ It is also irresistible to note that, using Hayles words again, "to suppose that such parallels require direct lines of influence is to be wedded to the very notions of causality that a field model renders obsolete." 1

In this study, the word "systems" has been used to indicate a way of thinking that focuses on the connections between things. In a 
system all elements are related to all other elements, and the whole is more than just the sum of its separate parts. Brief attention is given to some uses of systems thinking in philosophy, physics, psychology, cybernetics, sociology, and in connection with art and literary criticism.

In terms of things that might be found in works of art, theater and literature, systems thinking has certain definable implications. Such implications can easily be associated with many of the changes that have occurred in those arts since the late nineteenth century. For example, the idea that each element interacts with every other element suggests that the work may have a structure that is not sequential or spatial in the traditional manner of the past several centuries. A system tends toward: overallness, a merging of figure and ground; connection with other systems; extension to include the viewer; breakdown of sequentially; simultaneity; and non-linearity.

In works of art based on the systems paradigm, the structures and relationships of the sytem may be as visible, or more visible, than images, characters, or plot. Works of art have always been structured according to the needs of the artist, but it was a structure that quietly supported the content of the images or story. When that form first became visible, it was discussed as though it was separate from the images; as though the images and events were the content, the structure another thing. Both artists and writers were not saying something and providing a form for it separately. When they abandoned images and events to focus on the structure exclusively, critics recognized that the structure is also content.

It is the purpose of this study to: review, in layman's language, some definitions of the newer paradigm; investigate the early signs of paradigm change in the arts; and, take a more comprehensive look at three artists and writers whose work contains clear examples of the emerging paradigm. The criteria deduced by the author from an investigation of the systems paradigm is used as a 
basis for analyzing examples of visual arts, literature, theatre, and film. The bulk of this work is devoted to discovering ways in which systems thinking appeared in the arts even as systems became the focus of scientific investigations and philosphical discussions.

Part One includes definitions of terms and considerations of the nature of the changing paradigm in areas other than the arts. Part Two investigates the emergence of the systems paradigm in the works of visual artists, writers and dramatists at the turn of the century. The three artists and writers chosen for more concentrated attention in Part Three (Braque, Virgina Woolf, and Eisenstein) are among those that were produced by the turn-of-the-century era. Their work contains, clearly and consciously, indications of the emerging systems paradigm. Like many of their contemporary artists and writers, these three made a continuing effort to discover and communicate the reality of the world they represented. It was a reality that, they felt, could not be captured in naturalistic terms. The author's conclusions will be discussed in Part Four.

The idea of change is basic to this study. Change is something that many in our culture seem to have found alternately distressing and admirable for its own sake. From either of those extremes, it was difficult to see the nature of the change that is happening. It may require only the slightest shift of attention to look from the object to the field, from the thing to the system, but it makes an enormous difference in what we see. There has also been a change in how we look, or where we are looking from. The historical information covered here is not new. What is needed, in order to define the nature of our art forms and our culture, and to clarify the significance of what we teach in art classes, is not new data so much as a change of vision.

\section{Footnotes:}

1 Thomas S. Kuhn, The Structure of Scientific Revolutions, 2nd ed. 
Chicago: Chicago UP, 1970)

2 N. Katherine Hayles, The Cosmic Web: Scientific Field Models and

Literary Strategies in the Twentieth Century (Ithaca: Cornell UP, 1984) 25.

${ }^{3}$ Stephen Kern, The Culture of Time and Space, 1880-1918 (C ambridge: Harvard UP, 1983) 6.

4 Alan J. Friedman and Carol C. Donley, Einstein as Myth and Muse Cambridge: Cambridge UP, 1985) 84.

5 Milic Cakek, Bergson and Modern Physics: a Reinterpretation and R7evaluation. Boston Studies in the Philosophy of Science, vol VII,

Eds. Robert S. Cohen and Marx W. Watrofsky (Dordrecht, Holland: D. Reidel, 1971) 309.

6 Hayles, 22. 